\title{
High-intensity Interval Training Improves Inflammatory Mediators in Obese Women: Based on the Study of the UCP2 Ala55Val Gene
}

\author{
Susiana Candrawati ${ }^{1,2 *}$ (D), Emy Huriyati ${ }^{3}$, Zaenal Muttaqien Sofro ${ }^{4}$, Lantip Rujito ${ }^{5}$, Aulia Nury Faza ${ }^{6}$, Oktavia Nur Rohmawati ${ }^{6}$, \\ Amelinda Rifdah Aqiilah iD $^{6}$ \\ ${ }^{1}$ Department of Physiology, Medical Faculty, Jenderal Soedirman University, Purwokerto, Indonesia; ${ }^{2}$ Doctoral Study Program, \\ Faculty of Medicine, Public Health and Nursing, Gadjah Mada University, Yogyakarta, Indonesia; ${ }^{3}$ Department of Health \\ Nutrition, Faculty of Medicine, Public Health and Nursing, Gadjah Mada University, Yogyakarta, Indonesia; ${ }^{4}$ Department of \\ Physiology, Faculty of Medicine, Public Health and Nursing, Gadjah Mada University, Yogyakarta, Indonesia; ${ }^{5}$ Department \\ of Molecular Biology, Medical Faculty, Jenderal Soedirman University, Purwokerto, Indonesia; ${ }^{6}$ Department of ???, Medical \\ Faculty, Jenderal Soedirman University, Purwokerto, Indonesia
}

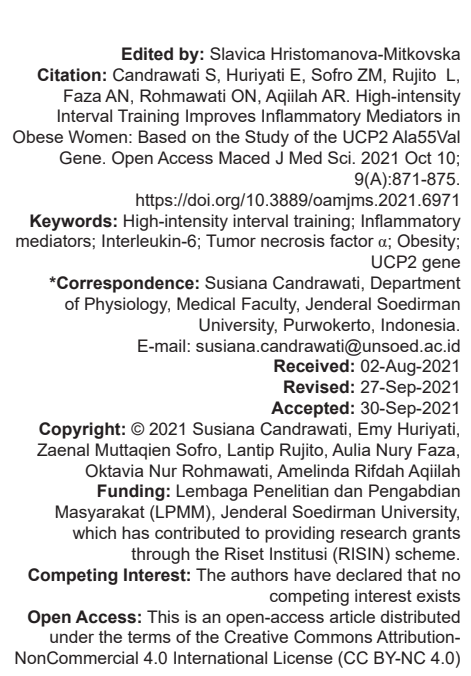

Introduction

Obesity is a condition of fat accumulation in adipose tissue that affects health. The worldwide prevalence of obesity is increasing from year to year. By 2030 , it is estimated that $20 \%$ of the adult population has the potential to become obese [1].

Obesity happens when fatty acids accumulate in adipocytes which result in cells hypertrophy and hyperplasia. Hypertrophic adipocytes secrete inflammatory substances that will attract macrophages which then infiltrate adipose tissue. Macrophages then stimulate the release of adipokines, including inflammatory mediators such as tumor necrosis factor (TNF)- $\alpha$ and interleukin (IL)-6 [2], [3].
Excessive secretion of inflammatory mediators will damage endothelial cells, cause vascular occlusion, reduce regional blood flow, and increase endothelium permeability. TNF- $\alpha$ and IL- 6 are cytokines involved in the systemic inflammatory response, but they have also been associated with insulin resistance and diabetes [4]. Increased inflammatory mediators in obesity are associated with metabolic syndrome. Therefore, obesity is also referred as the base pathogenesis for other diseases such as metabolic syndrome. Controlling inflammatory mediators in obese patients also prevent obesity from developing into metabolic syndrome, which is a complication of obesity.

Exercise is an effective effort to reduce the incidence of obesity. The high-intensity interval training (HIIT) program is an exercise which includes 
combination of high-intensity exercise and rest periods [5]. HIIT is considered a training that is time effective and reduces body fat levels. The mechanism of fat loss in HIIT is thought to be related to excess post-exercise oxygen consumption (EPOC). EPOC is defined as oxygen consumption that still occurs seven after physical exercise is completed [6]. Large EPOC means greater total energy expenditure. The amount of the EPOC is linearly related to the training volume but is also exponentially related to the training intensity [6]. The higher the intensity of exercise, such as in HIIT, the higher the EPOC. The decrease in body fat levels due to physical training will further affect inflammatory mediators such as IL- 6 and TNF- $\alpha$.

Besides training factor, genetic also plays a role on obesity. One of the genes that influence obesity is the UCP2 Ala55Val gene. Variation of the UCP2 Ala55Val gene has been associated with the $24 \mathrm{~h}$ energy output [7], [8], [9]. In addition, variation in the UCP2 Ala55Val gene mutates the amino acid alanine (GCC) to valine (GTC) at codon number 55. This mutation affects a decrease in resting energy expenditure $24 \mathrm{~h}$ and a reduction in the rate of fat oxidation so that it can increase the risk of obesity [10].

Therefore, this research aims to determine the effect of HIIT on the levels of inflammatory mediators in obese patients based on the study of the Ala55ValUCP2 gene. Exercise therapy based on gene variation can contribute to the therapy on preventing obesity complications.

\section{Methods}

This study was a quasi-experimental pre- and post-design without control group. The subjects were given HIIT as an intervention by comparing the data before and after the intervention. The intervention was conducted for 12 weeks, consisting of 2 weeks of adaptation and 10 weeks of HIIT intervention.

A purposive sampling method was used to collect this study population. The sample size required 30 obese women (body mass index $[\mathrm{BMI}] \geq 25 \mathrm{~kg} / \mathrm{m}^{2}$ ). The sample size was calculated using the formula for paired numerical analytical research.

$$
N=2\left[\frac{(Z \alpha+Z \beta) S}{x_{1}-x_{2}}\right]_{2}
$$

The inclusion criteria for study subjects were 18-34 years old, had a history of inactive lifestyle for the past 6 months, were declared healthy and fit for physical exercise, and were willing to be the subjects. Subjects taking weight loss drugs/supplements were excluded from the study. The dropout criteria were that they could not finish the intervention according to the predetermined program.

\section{Measurement of research variables}

Body composition measurement on BMI used data on body weight (BW) and height $(\mathrm{H})$ and the formula for BW $(\mathrm{kg}) / \mathrm{height}\left(\mathrm{m}^{2}\right)$ in units of $\mathrm{kg} / \mathrm{m}^{2}$. Measurement of inflammatory mediators, both TNF- $\alpha$ and IL-6, using the ELISA method, with units of $\mathrm{pg} / \mathrm{mL}$. The examination of the genetic variation of UCP2-Ala55Val used the polymerase chain reaction-restriction fragment length polymorphism (PCR-RFLP) method. The PCR-RFLP method was based on the digestion of PCR amplicons with appropriate restriction enzymes to produce distinct polymorphic fragments used as markers for species identification.

\section{Training intervention}

Training interventions were conducted for 12 weeks, with a frequency of 3 times/week and based on the COVID-19 prevention health protocol. The type of training was cycling. HIIT is an intermittent period of exercise separated by a recovery period. The 2 weeks of training adaptation were performed with an exercise regimen of $3 \times 3 \mathrm{~min}$ intervals (85-95\% maximum heart rate $[H R])$ and $4 \times 4 \mathrm{~min}$ of rest/recovery (60\% maximum $H R)$. The 10 weeks of intervention were performed with an exercise regimen of $4 \times 4$ min intervals (85-95\% maximum $\mathrm{HR}$ ) and $3 \times 3 \mathrm{~min}$ of rest/recovery $(60 \%$ maximum HR) [11], [12].

\section{Data analysis}

The BW, BMI, and inflammatory mediators (TNF- $\alpha$ and IL-6) before and after the intervention were analyzed using the dependent t-test and Wilcoxon test as a non-parametric test. Independent t-test and Mann-Whitney U-test used to determine the effect of the UCP2 Ala55Val gene on changes in BW, BMI, and the inflammatory mediator. The test results were considered significantly different if $p<0.05$.

\section{Research ethics}

The study had received an Ethics Committee Approval from the Medical and Health Research Ethics Committee Faculty of Medicine, Public Health and Nursing Universitas Gadjah Mada-DR. Sardjito General Hospital (Ref. No: KE/FK/0258/EC/2020). 
Table 1: Characteristics of research subject

\begin{tabular}{lllll}
\hline Variable & $\mathrm{n}$ & Mean $\pm \mathrm{SD}$ & Median & Min-max \\
\hline Age & 30 & $23.73 \pm 5.15$ & 21.0 & $18.00-34.00$ \\
BW pre-intervention & 30 & $73.54 \pm 11.99$ & 73.45 & $51.40-104.70$ \\
BW post-intervention & 30 & $72.16 \pm 11.42$ & 71.85 & $51.30-102.60$ \\
BMI pre-intervention & 30 & $29.57 \pm 4.80$ & 29.05 & $23.10-44.70$ \\
BMI post-intervention & 30 & $29.00 \pm 4.50$ & 28.25 & $22.50-43.80$ \\
IL-6 pre-intervention & 30 & $4.08 \pm 1.33$ & 4.17 & $1.18-8.17$ \\
IL-6 post-intervention & 30 & $2.67 \pm 0.85$ & 2.48 & $1.57-5.85$ \\
TNF-a pre-intervention & 30 & $4.43 \pm 1.98$ & 4.06 & $2.65-10.58$ \\
TNF-a post-intervention & 30 & $3.39 \pm 0.74$ & 3.15 & $2.33-5.36$ \\
\hline BMl: Body mass index, BW: Body weight, TNF: Tumor necrosis factor. & &
\end{tabular}

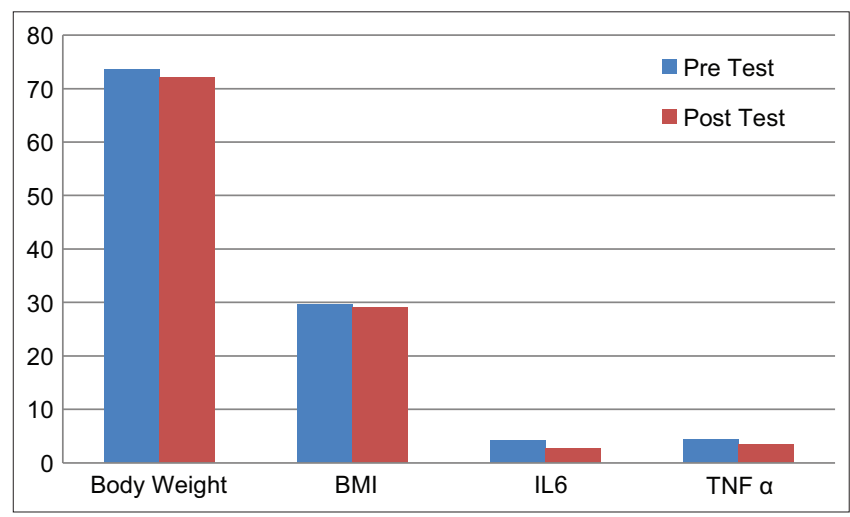

Figure 1: Characteristics of research subject based on intervention

\section{Results}

Table 1 shows BW, BMI, IL-6, and TNF- $\alpha$ results before and after an intervention.

Based on Table 1 and Figure 1, there was an improvement in BW, BMI, IL-6, and TNF- $\alpha$ after the HIIT.

Bivariate analysis used to determine whether exercise training interventions affect BW, BMI, and IL-6 using dependent t-test. Wilcoxon test used to determine whether exercise training interventions affect TNF- $\alpha$.

Table 2: The effect of HIIT on BW, BMI, and IL-6

\begin{tabular}{llll}
\hline Variable & $\mathrm{n}$ & Mean $\pm \mathrm{SD}$ & p value \\
\hline BW pre-intervention & 30 & $73.54 \pm 11.99$ & 0.0001 \\
BW post-intervention & 30 & $72.16 \pm 11.42$ & \\
BMI pre-intervention & 30 & $29.57 \pm 4.80$ & 0.0001 \\
BMI post-intervention & 30 & $29.00 \pm 4.50$ & \\
IL-6 pre-intervention & 30 & $4.08 \pm 1.33$ & 0.0001 \\
IL-6 post-intervention & 30 & $2.67 \pm 0.85$ & \\
TNF- $\alpha$ pre-intervention & 30 & $4.43 \pm 1.98$ & 0.0001 \\
TNF- $\alpha$ post-intervention & 30 & $3.39 \pm 0.74$ & \\
\hline HIIT: High-intensity interval training, BMI: Body mass index, BW: Body weight, TNF: Tumor necrosis factor.
\end{tabular}

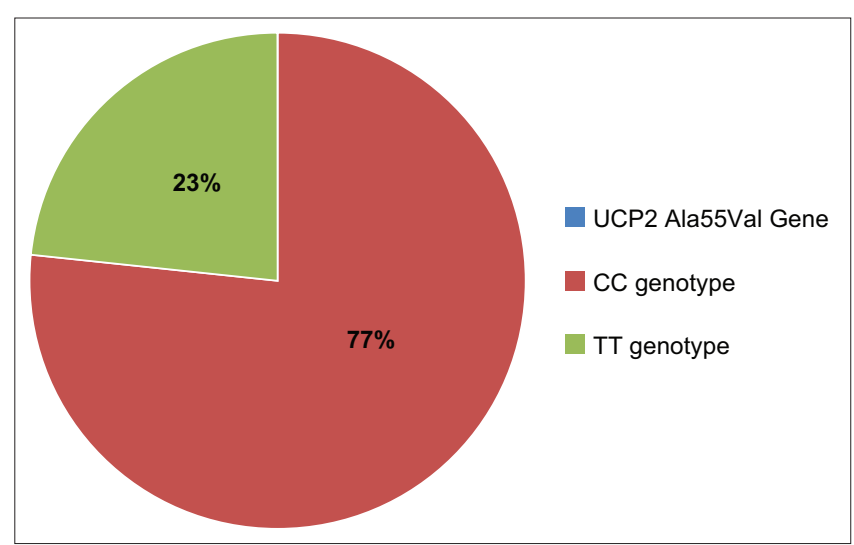

Figure 2: UCP2 Ala55Val distribution
Table 2 shows that HIIT significantly improved BW, BMI, IL-6, and TNF- $\alpha$ with $p<0.05$.

The genetic variation of UCP2 Ala55Val is expected to influence energy expenditure, thus affecting the development of obesity. A total of 30 study subjects were conducted to the UCP2 Ala55Val examination. The genotype results were that 23 subjects $(76.7 \%)$ had the Ala55 (CC) variant, and 7 study subjects $(23.3 \%)$ had the Val55 (TT) variant. There was no CT variant in the study subject (Figure 2).

Independent t-test was used to analyze the effect genetic variation on the response of BW, BMI, and TNF- $\alpha$. To analyze the effect of genetic variation on the response of IL-6, Mann-Whitney U-test was used because the data were not normally distributed. Table 3 shows the effect of genetic variation on the response to training, there were no differences in BW, BMI, IL-6, and TNF- $\alpha$ improvement in the two genotypes of the UCP2 Ala55Val gene.

Table 3: The effect of UCP2 Ala55Val gene on training responses of BW, BMI, and TNF- $\alpha$

\begin{tabular}{llll}
\hline Variable & $\mathrm{n}$ & Mean difference & p-value \\
\hline Delta on BW & & & \\
$\quad$ The Ala55genotype (CC) & 23 & $1.75 \pm 1.81$ & 0.719 \\
$\quad$ The Val55 genotype (TT) & 7 & $1.49 \pm 0.99$ & \\
Delta on BMI & & & \\
$\quad$ The Ala55genotype (CC) & 23 & $0.71 \pm 0.73$ & 0.663 \\
$\quad$ The Val55 genotype (TT) & 7 & $0.59 \pm 0.38$ & \\
Delta on TNF- $\alpha$ & & $1.39 \pm 1.91$ & 0.264 \\
$\quad$ The Ala55genotype (CC) & 23 & $0.56 \pm 0.33$ & \\
$\quad$ The Val55 genotype (TT) & 7 & & \\
Delta on IL-6 & & & \\
$\quad$ The Ala55genotype (CC) & 23 & $1.85 \pm 1.23$ & \\
$\quad$ The Val55 genotype (TT) & 7 & $1.25 \pm 0.42$ & \\
\hline BMl: Body mass index, BW: Body weight, TNF: Tumor necrosis factor. &
\end{tabular}

\section{Discussion}

This study was conducted on female subjects with obesity. Obesity is a chronic low-grade inflammatory condition characterized by an increased in inflammatory mediators, such as IL- 6 and TNF- $\alpha$. IL- 6 and TNF- $\alpha$ as inflammatory mediators are associated with obesity complications that begin with chronic inflammation and long-term insulin resistance. IL-6 works by inducing phosphorylation of tyrosine insulin receptor substrate 1 so that insulin cannot bind to its receptor [13]. However, in this study, the data showed IL-6 levels in subjects (obese women) were still at normal levels $(<11 \mathrm{pg} / \mathrm{ml})$. This may be because the research subjects were healthy obese women, that is, they do not have chronic diseases, allergies, and acute or chronic infections (in subjects' inclusion and exclusion criteria).

This study proved that HIIT can improve BMI and inflammatory mediators in obese patients. The results of this study were aligned with the research conducted by Neto (2016). Neto investigated the effect of HIIT on IL- 6 and TNF- $\alpha$ levels in overweight and obese adults. HIIT was considered to significantly reduce IL-6 
levels from a mean of $3.5 \pm 2.2 \mathrm{pg} / \mathrm{ml}$ to $2.4 \pm 2.0 \mathrm{pg} / \mathrm{ml}$ after 16 weeks of intervention. The study also showed a higher reduction of TNF- $\alpha$ than this study, which was $2.0 \mathrm{pg} / \mathrm{ml}$. This may be because of the difference in duration and frequency of the intervention. Neto's study was conducted for 16 weeks, whereas it was only 12 weeks in this study. The training program in Neto's study used the walking/running method on a treadmill for 16 weeks with a frequency of $5 \times /$ week, $30 \mathrm{~min}$, and an intensity of $70 \%$ maximum HR [14].

Research conducted by Ahmadizad (2015) showed different results. There was no significant change in IL-6 levels before and after HIIT intervention [15]. This was due to a shorter training period of 6 weeks and a different training method like walking or running. Regular intensity and duration of activity can also affect cytokine responses [16].

Factors that can influence physical exercise on IL- 6 and TNF- $\alpha$ levels are the characteristic and the intensity of the training [16]. HIIT consists of a short period of high-intensity physical exercise followed by a period of rest. On a long term, HIIT can reduce body fat mass. Reduced fat will cause a decrease in macrophage invasion in adipose tissue, thereby reducing the production of inflammatory mediators such as IL-6 and TNF- $\alpha$. Therefore, long-term HIIT has a significant effect on lowering IL-6 and TNF-a levels. Decreased IL-6 and TNF- $\alpha$ will reduce the risk of obesity developing into other diseases, such as metabolic syndrome [6], [17].

The results on the genetic variation of UCP2 Ala55Val study proved that there was no effect of genetic variation on the response to training. There was no difference between the CC and TT genotype variants in response to inflammatory mediators improvement after training intervention. The genetic variation of UCP2 Ala55Val can cause a decrease in energy expenditure, reduce fatty acid oxidation, and affect mRNA transcription and stabilization, which increased the risk of obesity [18]. The UCP2 gene is a biological candidate for a role in the regulation of the inflammatory response. The gene is expressed in a wide variety of cells, including spleen cells, macrophages, and T cells.

Moreover, the UCP2 protein functions as a downregulator of reactive oxygen species (ROS) generation [19]. In addition, ROS can activate the transcription factor NF-kB, which is ubiquitously expressed and mediates the expression of genes involved in the acute inflammatory response, including the cytokines IL1-IL6 and IL-8 [20]. However, the study could not prove the effect of UCP2 Ala55Val gene on inflammatory mediators improvement after training intervention.

The limitation of this study was unable to obtain a complete genetic variation of UCP2. From 30 research participants, only two genotype alleles were obtained, which are CC and TT. This study did not find genotype CT as UCP2 Ala55Val variation gene, so it was difficult to conclude the effect of UCP2 gene variation on improving inflammatory mediators on HIIT interventions. The small number of participants may decrease the power to detect differences between the intervention groups.

Based on the study's limitations, it can be suggested to take more participants and meet the availability of three types of genotypes in the Ala55Val UCP2 genetic variation.

\section{Conclusion}

The research concludes that the 12-week HIIT interventions improved inflammatory mediators by reducing IL-6 and TNF- $\alpha$ in obese women. HIIT can be used as a therapy for obese patients, mainly to prevent obesity complications by reducing inflammatory mediators. There was no effect of the UCP2 Ala55Val genetic variation on the response to training intervention.

\section{Applicable Remarks}

HIIT can be used as an alternative therapy for people with obesity, mainly to prevent obesity complications. To determine the effect of the Ala55Val UCP2 gene further research is required, with a larger number of participants and the availability of a complete Ala55Val UCP2 genotype.

\section{References}

1. Hruby A, Hu FB. The epidemiology of obesity: A big picture. Pharmacoeconomics. 2016;33(7):673-9.

PMid:25471927

2. Fernández-Sánchez $A$, Madrigal-Santillán $E$, Bautista $M$ Esquivel-Soto J, Morales-González A, Esquivel-Chirino C, et al. Inflammation, oxidative stress, and obesity. Int J Mol Sci. 2011;12(5):3117-32. https://doi.org/10.3390/ijms12053117 PMid:21686173

3. Ellulu MS, Patimah I, Khaza'ai H, Rahmat A, Abed Y. Obesity and inflammation: The linking mechanism and the complications. Arch Med Sci. 2017;13(4):851-63. https://doi.org/10.5114/ aoms.2016.58928

PMid:28721154

4. McArdle M, Finucane $\mathrm{O}$, Connaughton $\mathrm{R}$, McMorrow A, Roche $\mathrm{H}$. Mechanisms of obesity-induced inflammation and insulin resistance: Insights into the emerging role of nutritional strategies. Front Endocrinol. 2013;4:52. https://doi.org/10.3389/ fendo.2013.00052

PMid:23675368 
5. Keating SE, Johnson NA, Mielke GI, Coombes JS. A systematic review and meta-analysis of interval training versus moderateintensity continuous training on body adiposity. Obes Rev. 2017;18(8):943-64. https://doi.org/10.1111/obr.12536 PMid:28513103

6. Alahmadi MA. High-intensity interval training and obesity. J Nov Physiother. 2014;4(3):211.

7. Esterbauer H, Schneitler C, Oberkofler H, Ebenbichler $\mathrm{C}$, Paulweber B, Sandhofer F, et al. A common polymorphism in the promoter of UCP2 is associated with decreased risk of obesity in middle-aged humans. Nat Genet. 2001;28(2):178-83. http://doi.org/10.1038/88911

8. Krempler $\mathrm{F}$, Esterbauer $\mathrm{H}$, Weitgasser $\mathrm{R}$, Ebenbichler $\mathrm{C}$, Patsch JR, Miller $\mathrm{K}$, et al. A functional polymorphism in the promoter of UCP2 enhances obesity risk but reduces type 2 diabetes risk in obese middle-aged humans. Diabetes. 2002;51(11):3331-5. http://doi.org/10.2337/diabetes.51.11.3331 PMid: 12401727

9. Dalgaard LT. Genetic variance in uncoupling protein 2 in relation to obesity, Type 2 diabetes, and related metabolic traits: Focus on the functional -866G>A promoter variant (rs659366). J Obes. 2011;2011:340241. http://doi.org/10.1155/2011/340241 PMid:21603268

10. Gamboa R, Huesca-Gómez C, López-Pérez V, Posadas- Sánchez R, Cardoso-Saldaña G, Medina-Urrutia A, et al. The UCP2 -866G/A, Ala55Val and UCP3 -55C/T polymorphisms are associated with premature coronary artery disease and cardiovascular risk factors in Mexican population. Genet Mol Biol. 2018;41:371-8.

11. Weston KS, Wisløff U, Coombes JS. High-intensity interval training in patients with lifestyle-induced cardiometabolic disease: A systematic review and meta-analysis. $\mathrm{Br} \mathrm{J}$ Sports Med. 2014;48(16):1227-34. http://doi.org/10.1136/ bjsports-2013-092576 PMid:24144531

12. Wijtzes Al, Bouthoorn $\mathrm{SH}$, Jansen W, Franco OH, Hofman A Jaddoe VW, et al. Sedentary behaviors, physical activity behaviors, and body fat in 6-year-old children: The generation R study. Int J Behav Nutr Phys Act. 2014;11:96. http://doi.org/10.1186/PREACCEPT-1946502959127020 PMid:25124336

13. Pal R, Singh SN, Chatterjee A, Saha M. Age-related changes in cardiovascular system, autonomic functions, and levels of BDNF of healthy active males: Role of yogic practice. Age (Omaha). 2014;36(4):9683. http://doi.org/10.1007/s11357-014-9683-7 PMid:25012275

14. Gerosa-Neto J, Antunes BM, Campos EZ, Rodrigues J, Ferrari GD, Neto JC, et al. Impact of long-term high-intensity interval and moderate-intensity continuous training on subclinical inflammation in overweight/obese adults. J Exerc Rehabil. 2016;12(6):575-80. http://doi.org/10.12965/jer.1632770.385 PMid:28119880

15. Ahmadizad S, Avansar AS, Ebrahim K, Avandi M, Ghasemikaram M. The effects of short-term high-intensity interval training vs. moderate-intensity continuous training on plasma levels of nesfatin-1 and inflammatory markers. Horm Mol Biol Clin Investig. 2015;21(3):165-73. http://doi.org/10.1515/ hmbci-2014-0038.

PMid:25581765

16. Calle MC, Fernandez ML. Effects of resistance training on the inflammatory response. Nutr Res Pract. 2010;4(4):259-69. http://doi.org/10.4162/nrp.2010.4.4.259

PMid:20827340

17. Rodrigues AC, Leal TF, Costa AJ, de Silva FJ, Soares LL, Brum PC, et al. Effects of aerobic exercise on the inflammatory cytokine profile and expression of lipolytic and thermogenic genes in $\beta 1$-AR mice adipose tissue. Life Sci. 2019;221:224- 32. http:// doi.org/10.1016/j.lfs.2019.02.031

PMid:30771314

18. Lapice E, Pinelli M, Pisu E, Monticelli A, Gambino R, Pagano G, et al. Uncoupling protein $2 \mathrm{G}(-866) A$ polymorphism: A new gene polymorphism associated with C-reactive protein in Type 2 diabetic patients C-reactive protein in Type 2 diabetic patients. Cardiovasc Diabetol. 2010;9:1-5.

19. Arsenijevic D, Onuma $H$, Pecqueur $C$, Raimbault $S$, Manning BS, Miroux B, et al. Disruption of the uncoupling protein-2 gene in mice reveals a role in immunity and reactive oxygen species production. Nat Genet. 2000;26(4):435-9. http:// doi.org/10.1038/82565 PMid: 11101840

20. Fialkow L, Wang Y, Downey GP. Reactive oxygen and nitrogen species as signaling molecules regulating neutrophil function. Free Radic Biol Med. 2007;42(2):153-64. http://doi. org/10.1016/j.freeradbiomed.2006.09.030 PMid:17189821 